\title{
Quantifying seascape structure: extending terrestrial spatial pattern metrics to the marine realm
}

\author{
Lisa M. Wedding ${ }^{1,2, *}$, Christopher A. Lepczyk ${ }^{3}$, Simon J. Pittman ${ }^{2,4}$, \\ Alan M. Friedlander ${ }^{5}$, Stacy Jorgensen ${ }^{1}$ \\ ${ }^{1}$ University of Hawaii at Manoa, Department of Geography, Saunders Hall 445, Honolulu, Hawaii 96822, USA \\ ${ }^{2}$ National Oceanic \& Atmospheric Administration Biogeography Branch, 1305 East West Highway, Silver Spring, \\ Maryland 20910, USA \\ ${ }^{3}$ University of Hawaii at Manoa, Department of Natural Resources and Environmental Management, 1910 East-West Road, \\ Honolulu, Hawaii 96822, USA \\ ${ }^{4}$ Marine Science Center, University of the Virgin Islands, 2 John Brewers Bay, St. Thomas, US Virgin Islands 00802, USA \\ ${ }^{5}$ US Geological Survey Hawaii Cooperative Fisheries Research Unit, 2538 McCarthy Mall, Honolulu, Hawaii 96822, USA
}

\begin{abstract}
Spatial pattern metrics have routinely been applied to characterize and quantify structural features of terrestrial landscapes and have demonstrated great utility in landscape ecology and conservation planning. The important role of spatial structure in ecology and management is now commonly recognized, and recent advances in marine remote sensing technology have facilitated the application of spatial pattern metrics to the marine environment. However, it is not yet clear whether concepts, metrics, and statistical techniques developed for terrestrial ecosystems are relevant for marine species and seascapes. To address this gap in our knowledge, we reviewed, synthesized, and evaluated the utility and application of spatial pattern metrics in the marine science literature over the past 30 yr (1980 to 2010). In total, 23 studies characterized seascape structure, of which 17 quantified spatial patterns using a 2-dimensional patch-mosaic model and 5 used a continuously varying 3-dimensional surface model. Most seascape studies followed terrestrial-based studies in their search for ecological patterns and applied or modified existing metrics. Only 1 truly unique metric was found (hydrodynamic aperture applied to Pacific atolls). While there are still relatively few studies using spatial pattern metrics in the marine environment, they have suffered from similar misuse as reported for terrestrial studies, such as the lack of a priori considerations or the problem of collinearity between metrics. Spatial pattern metrics offer great potential for ecological research and environmental management in marine systems, and future studies should focus on (1) the dynamic boundary between the land and sea; (2) quantifying 3-dimensional spatial patterns; and (3) assessing and monitoring seascape change.
\end{abstract}

KEY WORDS: Seascape ecology · Landscape indices · Landscape metrics · Seascape structure · Spatial pattern metrics $\cdot$ Spatial scale

\section{INTRODUCTION}

Landscape ecology has been widely applied in the terrestrial environment to understand the relationships between spatial patterns and ecological processes at a range of spatial and temporal scales (Forman \& Godron 1986, Turner 1989, Wiens 2002). In landscape ecology, the scientific study of spatial patterning requires the quantification of the structural geometry of landscapes (Gustafson 1998). To address this task, landscape ecologists have developed spatial tools and spatial pattern statistics specifically to quantify the geometric properties in mapped surfaces. There now exists a wide range of metrics for the 
examination of relationships between spatial structure, ecological function, and landscape change (Gustafson 1998). Spatial pattern metrics have been classified broadly into 3 categories that quantify: (1) landscape composition, e.g. the abundance and variety of patch types, without reference to spatial attributes of the geometry; (2) configuration, e.g. the spatial arrangement of individual patches and mosaics of patches; and (3) fractal dimension, e.g. the shape complexity of a patch or landscape (Turner et al. 2001, Mandelbrot 1982) (Table 1). Spatial pattern metrics provide a consistent method with which to compare landscape structure and to monitor change at a range of spatial scales, thus providing ecologists and resource managers with a suite of tools that have contributed to effective management decisions in conservation and planning (Botequilha Leitão et al. 2006).

Computer software has been produced by landscape ecologists and statisticians to facilitate the application of metrics. The most widely used landscape metric applications are the software packages FRAGSTATS (www.umass.edu/landeco/research/fragstats/fragstats .html) and Patch Analyst (http://flash.lakeheadu.ca/ rrempel/ecology/). Spatial pattern metrics can be quantified for both vector-based and raster-based maps (Fig. 1).

Like landscape ecology, the marine counterpart, seascape ecology, focuses on the causes and consequence of spatial patterning (Hinchey et al. 2008, Li \& Mander 2009), including implications of human activity (Costanza et al. 1990). Seascapes have been repre- sented using several different conceptual models with varying cartographic properties (i.e. spatial and thematic resolution). The 'patch-matrix' model is a common representation of seascape structure based conceptually upon island biogeography theory, where the map classification is binary with focal 'high quality' patches embedded in a matrix of 'lower quality' habitat (Fig. 2A). The focus of this patch-matrix model has been on patch attributes such as area (i.e. species-area relationships), biotic response to patch edges, perimeter:area ratios, patch shape, and inter-patch distances or isolation (Fig. 2B). More recently, entire mosaics of patches have also been examined to assess the effect of the seascape surrounding a focal patch, thereby providing information on the patch context (Brennan et al. 2002).

Conclusions on the suitability of landscape ecology concepts and techniques to marine ecosystems vary among studies, with some evidence that patch and seascape structure such as edges, patch size, and the spatial configuration and composition of patch mosaics have a significant influence on marine organisms (Grober-Dunsmore et al. 2009, Boström et al. 2011, this Theme Section). In contrast, for seagrass ecosystems, where the majority of research has been conducted, results from patch level studies have been equivocal and highly variable among species and ecosystems (Boström et al. 2006).

In general, landscape ecology concepts developed and evaluated primarily for terrestrial environments have been used in marine studies on the assumption

Table 1. Summary of commonly used metrics for quantifying landscape pattern from 2D categorical maps arranged into 3 broad categories following Turner et al. (2001) and McGarigal et al. (2002). Algorithms and descriptions of mathematical formulas are provided in McGarigal et al. (2002)

\begin{tabular}{|c|c|c|c|}
\hline Metric & Level & Type & Description \\
\hline \multicolumn{4}{|c|}{ (1) Landscape composition (quantifies type of landscape cover type present and relative amount) } \\
\hline Proportion & Mosaic & Structural & Proportion of landscape occupied by cover type \\
\hline Richness & Mosaic & Structural & Number of patch types composing the mosaic \\
\hline Evenness & Mosaic & Structural & Relative abundance of different patch types \\
\hline Diversity & Mosaic & Structural & Composite measure of richness and evenness \\
\hline \multicolumn{4}{|c|}{ (2) Spatial configuration (quantifies the spatial arrangement and orientation of patches/mosaic) } \\
\hline Contagion & Mosaic & Structural & $\begin{array}{l}\text { Distinguishes between overall clumped or dissected } \\
\text { mosaic patterns }\end{array}$ \\
\hline Patch area & Patch-based & Structural & Total area of patch \\
\hline Patch perimeter & Patch-based & Structural & Perimeter of a patch \\
\hline Perimeter:area ratio & Patch-based & Structural & Index of patch shape complexity \\
\hline Connectivity & Patch-based & Functional & Average distance between patches \\
\hline Proximity index & Patch-based & Structural & $\begin{array}{l}\text { Degree to which patches in landscape are isolated from } \\
\text { other patches }\end{array}$ \\
\hline $\begin{array}{l}\text { Area-weighted } \\
\text { average patch size }\end{array}$ & Patch-based & Structural & Frequency distribution of patch sizes \\
\hline Core area & Patch-based & Structural & Area unaffected by the edge of the patch \\
\hline \multicolumn{4}{|c|}{ (3) Fractal dimension (quantifies the shape complexity of a patch or landscape) } \\
\hline Mean patch fractal d & Patch-based & Structural & Average patch shape complexity \\
\hline
\end{tabular}




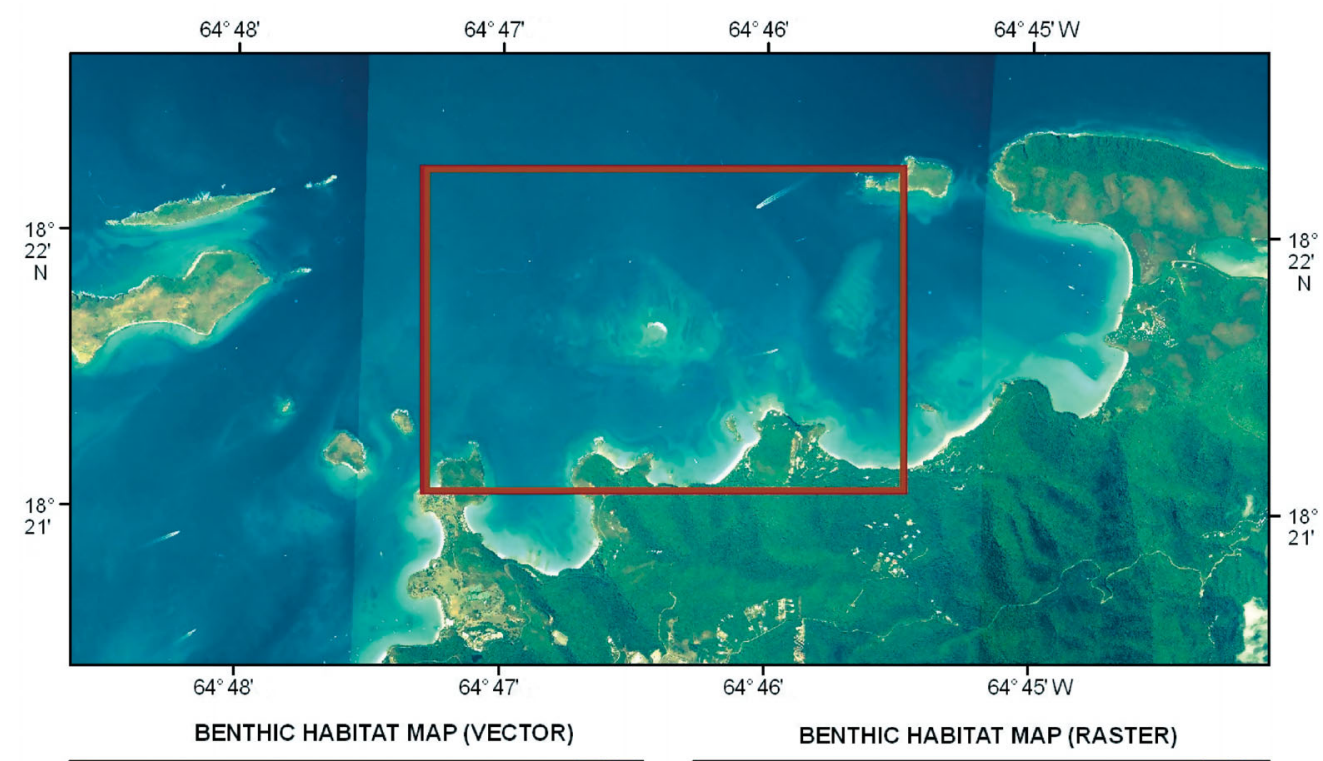

Fig. 1. Example of multiscaled approach to derive seascape metrics using NOAA Biogeography Branch benthic habitat maps of St John, US Virgin Islands; from vector data (bottom left), using the increasing radius approach, and raster data (bottom right), using the moving window approach
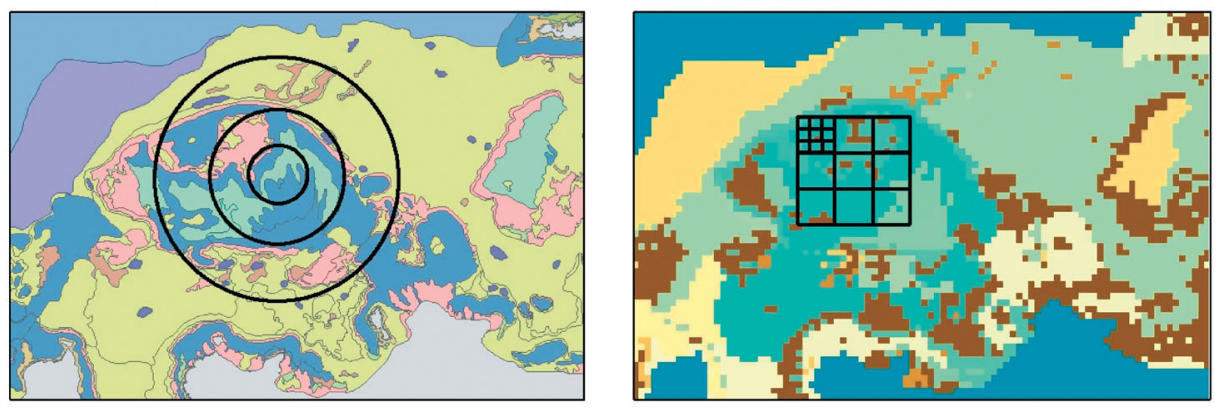

that the approach is equally applicable to marine species and habitats. The rationale for this assumption is that some generalities will exist in the organism and community response to structural patterns whether they are in water or in air. However, it is not yet known whether some of the fundamental differences between terrestrial and marine systems may affect the transfer of techniques from land to sea. Further, in landscape ecology studies that have applied spatial pattern metrics, the approach is often exploratory and the selection of metric(s) and the spatial scale of analyses are typically unsupported by ecological rationale. The lack of guidelines on utilizing and implementing landscape metrics in the marine environment presents a notable knowledge gap that requires urgent attention to support future applications of metrics to seascapes.

Considering the issues surrounding landscape metrics and their relatively recent rise in marine ecology, our overarching goal was to assess the potential for the application of spatial pattern metrics to seascapes. In order to address this goal, we had 3 key objectives: (1) determine how many studies have applied spatial pattern metrics to quantify seascapes; (2) highlight uniquely marine spatial pattern metrics; and (3) discuss the importance of considering spatial, temporal, and thematic resolution.

\section{METHODS AND SCOPE OF REVIEW}

Definitions of seascape ecology and spatial pattern metrics. Seascape ecology is the application of landscape ecology to the marine environment, and currently is almost entirely based on concepts and techniques developed for terrestrial species and habitats (Kneib 1994, Robbins \& Bell 1994). Within the context of this review, spatial pattern metrics, sometimes referred to as landscape metrics or indices, are applied to characterize and quantify the spatial structure of seascapes. Spatial pattern metrics have evolved from the original need to quantify the complex spatial heterogeneity represented in remotely sensed images (both aerial photography and satellite imagery). There are 2 major types of metrics that are applied to specific data types (e.g. point data, 2-dimensional [2D] categorical maps, and continuously varying 3D surfaces; Burrough 1981, Legendre \& Fortin 1989, Li \& Reynolds 1995, McGarigal et al. 2009). In this paper, we focused primarily on the quantification of spatial pattern metrics that are applied to 2D maps of the seafloor, such as benthic habitat maps (e.g. maps with horizontal patterning, but no vertical dimension). Marine ecologists are now also applying spatial pattern metrics (terrain metrics) to continuously varying 3D surface models; thus some examples are included in this review. 


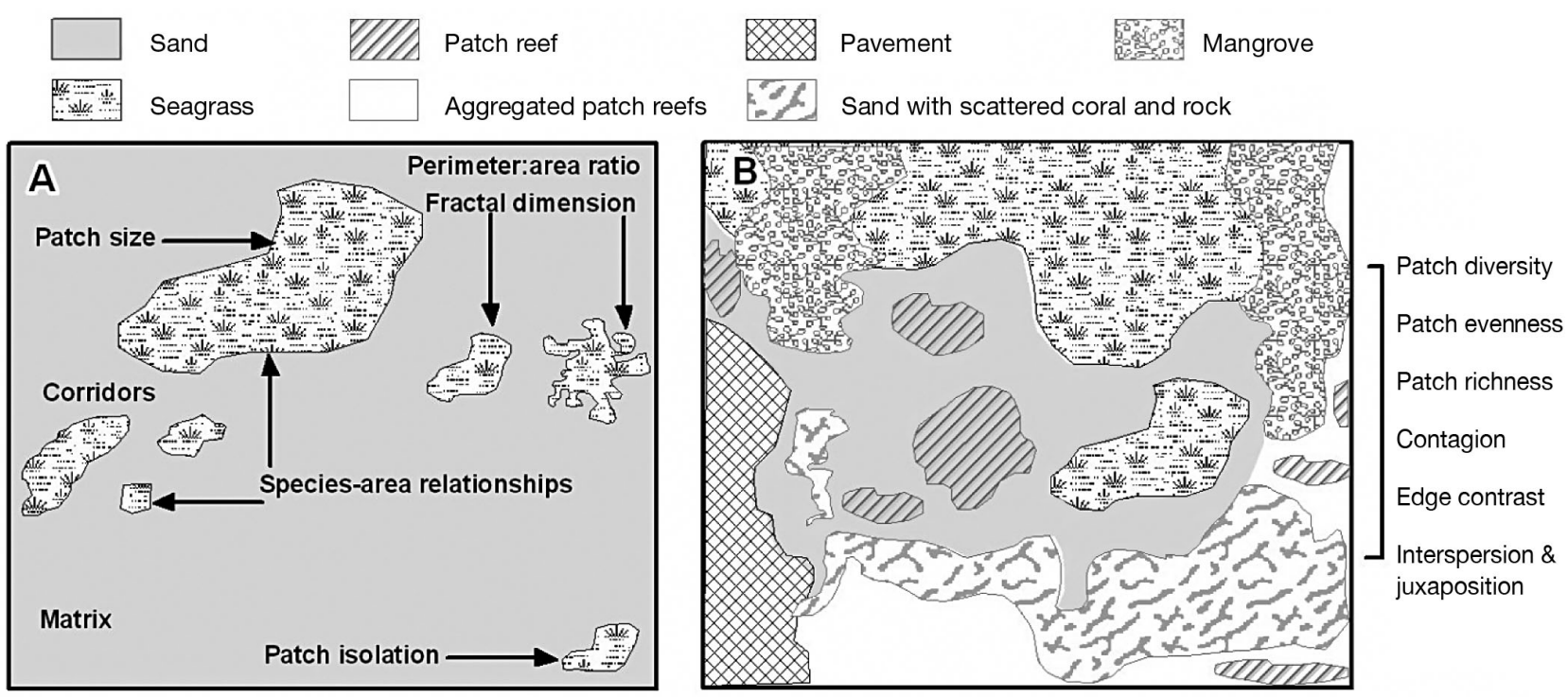

Fig. 2. Examples of 2 different seascape models. (A) Binary seascape with focal patches (seagrasses) that contrast sharply with the surrounding homogeneous and potentially 'hostile' matrix (bare sand). (B) Marine patch-mosaic model, where the seascape is spatially and compositionally complex, cannot be simply categorized into discrete binary elements

Literature search and selection. Marine applications of spatial pattern metrics were sourced primarily from the ISI Web of Knowledge's Web of Science (www. isiknowledge.com/) over a $30 \mathrm{yr}$ period (1980 to 2010) using relevant key words and search strings (Table 2 and see Table $\mathrm{S} 1$ in the supplement at www.int-res. com/articles/suppl/m427p219_supp.pdf). The asterisk was used as a wildcard in ISI to allow for singular or plural words to be identified in the same search. In addition to these articles from the ISI search, several supplementary articles were included in the review from bibliographic lists cited in these ISI articles. Research articles were examined and only included in this marine spatial pattern metric review if they met the following criteria:

(1) The article was published in a peer-reviewed journal in the English language.

(2) Spatial pattern metric(s) were used to quantify seascape structure in the article and not just mentioned in the text.

(3) Spatial pattern metric(s) were applied to 2D categorical maps or continuously varying 3D surfaces.

The articles examined were based on a review of a strictly qualified subset of the literature, and as a result, the conclusions are relevant specifically to studies that have applied spatial pattern metrics to marine environments. The studies were reviewed and attributes were recorded in a database that included author, article title, publication year, journal, volume, issue, key word, landscape pattern metric, quantification, data representation, data type, minimum mapping unit (MMU), and extent (Table S2 in the supplement).
Structure of the review and synthesis. Relevant papers were reviewed to examine (1) the number of studies that applied spatial pattern metrics to quantify seascapes; (2) uniquely marine spatial pattern metrics; and (3) importance of considering spatial, temporal, and thematic resolution. The results of the literature search are synthesized and organized by the 2 major groupings of metrics we have identified (e.g. 2D categorical maps and continuously varying 3D surfaces). From the selected papers and the broader literature on multivariate ecological modeling, we discuss and highlight many of the analytical techniques that have been used effectively to identify the most influential metrics, and to link this spatial variability to the ecology of spe-

Table 2. Key words used in ISI literature review for marine applications of spatial pattern metrics. The asterisk is used in ISI as a wildcard in order for singular or plural words to be identified in the same search. Numbers in the left column denote the key words used to find studies and are also used in Table S1 in the supplement
TERRESTRIAL
1. 'landscape metric ${ }^{* \prime}$
2. 'landscape indice ${ }^{* \prime}$

$\begin{array}{ll}\text { MARINE } & \\ 1 . & \text { 'seascape }{ }^{* \prime} \text { AND 'metric *' } \\ 2 . & \text { 'marine' AND 'landscape*' AND 'metric*' } \\ 3 . & \text { 'seascape }{ }^{* \prime} \text { AND 'indice*' } \\ 4 . & \text { 'marine' AND 'landscape*' AND 'indice*' } \\ \text { 5. } & \text { 'marine landscape ecology' } \\ 6 . & \text { 'seascape structure' }\end{array}$

\section{MARINE}

1. 'seascape *' AND 'metric*'

2. 'marine' AND 'landscape*' AND 'metric *'

6. 'seascape structure' 


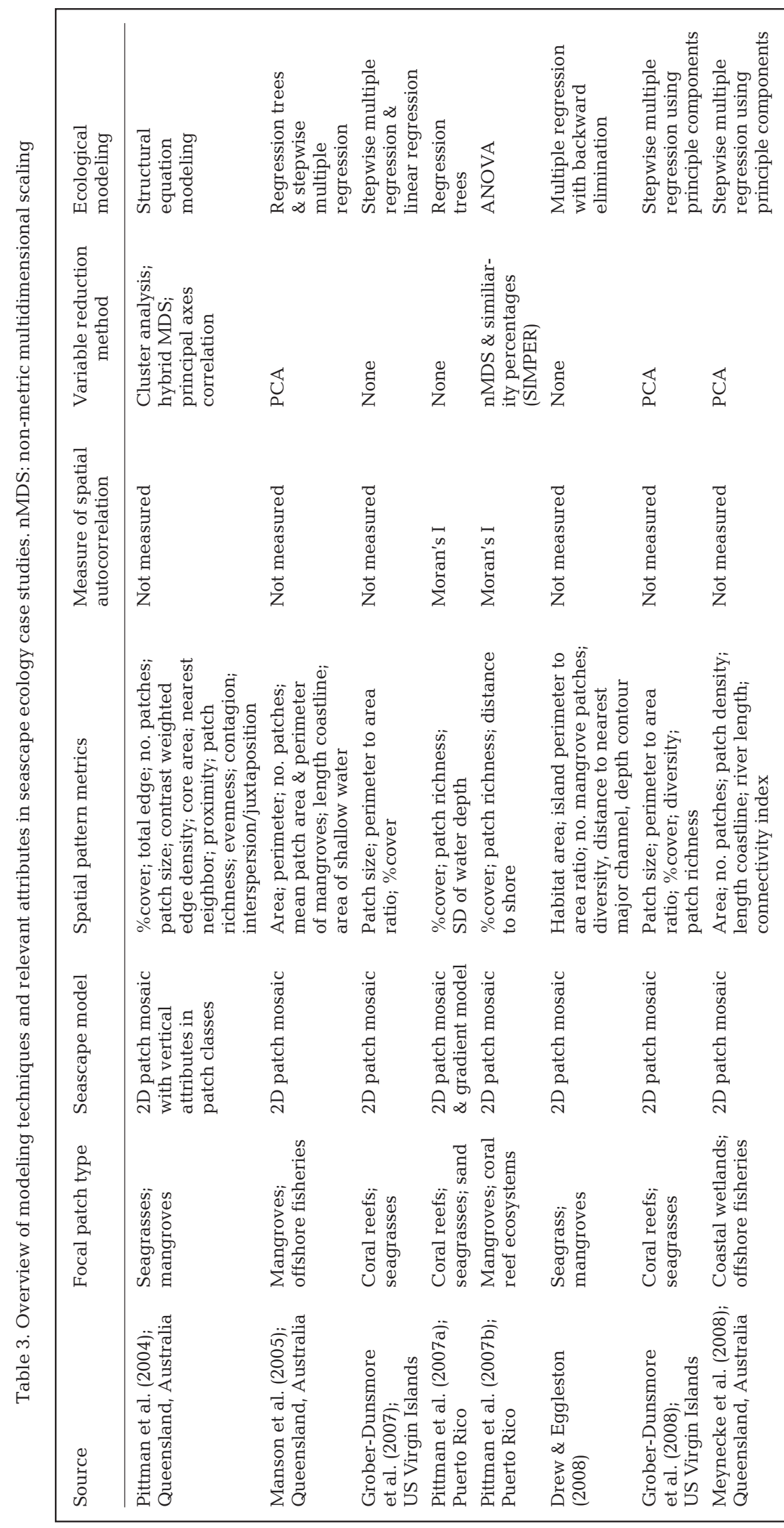

cies. The final 2 sections highlight current knowledge gaps and research questions to help guide future applications of spatial pattern metrics to the marine environment.

\section{RESULTS}

\section{Literature review}

Marine applications of landscape
metrics

The first published ecological studies using metrics to quantify spatial patterns emerged in the early 1980s for terrestrial systems (Romme 1982, Forman \& Godron 1986, Krummel et al. 1987, O'Neill et al. 1988). In the marine environment, edge metrics such as the amount of land-water interface were recognized as important predictors of coastal species distributions in the late 1980s (Browder et al. 1989), although the structural attributes of individual patches had been considered from at least the 1970s (e.g. species-area relationships; Neigel 2003). However, it was not until more recently that pattern metrics were applied to quantify marine habitat mosaic composition and configuration (Garrabou et al. 1998, Andréfouët et al. 2001). Metrics have now been applied to Antarctic benthos $\left(<10 \mathrm{~s}\right.$ of $\left.\mathrm{m}^{2}\right)$, and at broader spatial scales $\left(10 \mathrm{~s}\right.$ to $100 \mathrm{~s}$ of $\left.\mathrm{m}^{2}\right)$ to seagrass, saltmarsh, mangrove, and coral reef ecosystems (Table 3 ).

Over the past $30 \mathrm{yr}$, a total of 556 terrestrial research papers focused on the subject of landscape metrics (e.g. based on a 'landscape metric*' query in ISI) or indices (e.g. based on 'landscape indice*' query in ISI), compared to 40 marine papers that contained 1 or more of these search terms. Of the 40 marine studies, only 23 met our specific selection criteria that required the actual application of spatial pattern metrics to quantitatively measure seascape structure (Table S1 in the supplement). Consequently, this review focuses on these 
23 studies, of which 18 quantified spatial patterns from $2 \mathrm{D}$ categorical data and 5 applied surface metrics or morphometrics to continuously varying 3D surfaces (e.g. seafloor bathymetry from multibeam or light detection and ranging [LiDAR] data).

\section{Application to 2D seascapes}

The majority (78\%) of seascape studies quantified metrics based on a patch-mosaic model representing $2 \mathrm{D}$ seascape structure. Of the 18 seascape metric studies based on 2D data, 7 were conducted in estuarine, mangrove, and seagrass communities (Turner et al. 1999, Manson et al. 2003, 2005, Pittman et al. 2004, Sleeman et al. 2005, Drew \& Eggleston 2008, Meynecke et al. 2008), 6 studies were conducted in coral reef ecosystems (Andréfouët et al. 2001, Grober-Dunsmore et al. 2007, Pittman et al. 2007a,b, Grober-Dunsmore et al.
2008, Prada et al. 2008), 2 studies in Antarctic benthic communities (Teixido et al. 2002, 2007), and the remaining 2 in the subtidal zones of Mediterranean rocky shores (Garrabou et al. 1998, 2002).

Multiple spatial pattern metrics were applied to quantify landscape composition, and contagion spatial configuration (patch-based and mosaic), and patch complexity (patch-based) (Table 4; Table S2 in the supplement). Specifically, 10 of the studies applied metrics at the patch level (e.g. individual patch types) and 7 to entire seascape mosaics comprising multiple patch types. Nine metrics measuring landscape composition were applied, with patch area being the most prevalent metric $(n=5)$, followed by habitat diversity and richness $(n=3)$ and evenness $(n=2)$.

In total, 24 different spatial pattern metrics were applied to quantify the spatial arrangement, orientation, or shape of seascape patches. Most metrics were standard pattern metrics from terrestrial landscape

Table 4. Summary of 2D spatial pattern metrics applied in the reviewed literature. 'Contagion' quantifies the level of clumping or aggregation in landscape elements. ${ }^{*}$ Spatial pattern metrics adapted or developed uniquely for seascape ecology studies

\begin{tabular}{|c|c|c|}
\hline Spatial pattern metric & No. of studies & Major habitat type in study \\
\hline Landscape composition -9 metrics & & (of 7 studies using composition) \\
\hline Habitat area & 5 & Coral reef, Antarctic benthic, mangrove \\
\hline Habitat diversity & 3 & Coral reef, Antarctic benthic, mangrove \\
\hline Patch richness & 3 & Coral reef, Antarctic benthic \\
\hline Habitat richness & 2 & Coral reef \\
\hline Evenness & 2 & Coral reef, Antarctic benthic \\
\hline Habitat perimeter & 2 & Mangrove \\
\hline Patch diversity & 1 & Coral reef \\
\hline Percent cover & 1 & Coral reef \\
\hline Mean depth & 1 & Coral reef \\
\hline Spatial configuration (contagion) -2 metrics & & (of 2 studies using contagion) \\
\hline Interspersion & 1 & Antarctic benthic \\
\hline Contagion index & 1 & Intertidal \\
\hline Spatial configuration (patch-based) -22 metrics & & (of 10 studies using configuration) \\
\hline Patch mean size & 4 & Intertidal, coral reef, mangrove \\
\hline Number of patches & 4 & Mangrove, intertidal \\
\hline Perimeter:area ratio & 3 & Coral reef, mangrove \\
\hline Mean patch area & 2 & Mangrove, seagrass \\
\hline Mean patch perimeter & 2 & Mangrove, seagrass \\
\hline Mean shape index & 2 & Intertidal, mangrove \\
\hline Area weighted mean shape index & 1 & Intertidal \\
\hline Landscape shape index & 1 & Intertidal \\
\hline Patch size standard deviation & 1 & Intertidal \\
\hline Patch size coefficient of variation & 1 & Intertidal \\
\hline Total edge & 1 & Intertidal \\
\hline $\begin{array}{l}\text { * Coral habitat intersecting boundary/ } \\
\text { Coral habitat inside boundary }\end{array}$ & 1 & Coral reef \\
\hline Patch size variability & 1 & Intertidal \\
\hline Patch shape & 1 & Intertidal \\
\hline $\begin{array}{l}\text { Distance to nearest feature } \\
\text { (e.g. prop root) }\end{array}$ & 1 & Mangrove \\
\hline Coefficient of variation & 1 & Mangrove \\
\hline Mean proximity index & 1 & Mangrove \\
\hline * Mangrove-water interface & 1 & Mangrove \\
\hline * Length of coastline & 1 & Mangrove \\
\hline Fractal dimension & 1 & Seagrass \\
\hline Nearest neighbor & 1 & Seagrass \\
\hline * Hydrodynamic aperture & 1 & Coral reef \\
\hline
\end{tabular}


ecology (e.g. contagion, perimeter:area ratio, interspersion), with 5 being adapted specifically to the marine environment. The 1 truly unique marine metric we encountered was hydrodynamic aperture (total aperture and degree of aperture) developed to measure the morphological openings in the carbonate rims of Pacific atolls. Apertures are channels that allow water, nutrients, and biological exchanges between the ocean and the interior lagoon environments of atolls (Andréfouët et al. 2001, 2003). In addition, unique derivatives of commonly used terrestrial edge metrics have been developed for coastal wetlands, such as the linear extent of the mangrove-water interface (Manson et al. 2003), and the marsh-water interface used as a predictor of brown shrimp production in Louisiana saltmarshes (Browder et al. 1989). Bartholomew et al. (2008) developed an edge metric that quantified the ratio between marine reserve boundary that intersected coral reefs and the area of coral reefs within marine reserves. This metric provided a proxy for boundary permeability to examine the influence of reserve boundary placement on the retention potential of recovering exploited fish populations.

Mean patch size and number of patches $(n=4)$ were the most commonly applied metrics used to quantify seascapes, followed by perimeter to area ratio $(n=3)$, mean patch area, mean patch index, and mean patch perimeter $(n=2)$. Of the marine applications of pattern metrics, $67 \%$ involved an evaluation of the relationships between ecological patterns in the marine environment. Garrabou et al. (1998) characterized the spatial dynamics of mosaics of colonizing organisms on Mediterranean rocky shores using digital photographs and GIS to map benthic communities at relatively fine spatial scales $\left(310 \mathrm{~cm}^{2}\right.$ plots). At a broader scale, Meynecke et al. (2008) characterized the coastal seascape in Queensland, Australia, and applied metrics to determine the links between seascape structure and offshore fisheries productivity. In coral reef ecosystems, studies focused primarily on the influence of seascape structure on coral reef fish assemblages, trophic guilds, and species of concern. Two studies in the Caribbean explored the linkages between mangroves (Pittman et al. 2007a) and seagrass habitat (Grober-Dunsmore et al. 2007) for fish species and assemblages.

Seventeen percent of the studies applied metrics to monitor spatial dynamics across a range of temporal scales. Garrabou et al. (2002) utilized pattern metrics to monitor change of benthic communities on rocky subtidal substratum over a 2 yr period. Manson et al. (2003) applied 7 spatial pattern metrics to document change in mangrove communities from vegetation maps over a 25 yr period. In Antarctic benthic communities, Teixido et al. (2007) applied 2 metrics (class area and number of patches) to measure benthic community change across a gradient of disturbance due to iceberg scouring. Unlike terrestrial studies where change over time is a prominent component of studies, seascape studies have not pursued this to any notable degree, and this is an area of research that has great potential to expand in the future.

\section{Application to 3D seascapes}

Of the 5 seascape metric studies based on continuously varying 3D surfaces (e.g. LiDAR or multibeam derived bathymetry), 4 were conducted in coral reef ecosystems and the other study was carried out in shale beds off the coast of California (Table 5). The most commonly applied morphometric was rugosity $(\mathrm{n}=3)$, followed by slope and mean depth $(\mathrm{n}=2)$. Overall, 8 morphometrics were applied, of which 7 were used to quantify habitat complexity in the marine environment. For example, Wedding \& Friedlander (2008) found that variance in depth (within a $75 \mathrm{~m}$ radius) explained most of the variation in numerical abundance and species richness compared to other spatial pattern metrics applied to continuously varying 3D surface data. Pittman et al. (2009) compared 8 morphometrics at multiple spatial scales to identify the best predictors of fish and coral species richness and abundance. Slope of the slope, a measure of the habitat complexity, emerged as the most influential spatial predictor for a wide range of coral reef associated faunal species (Pittman et al. 2009).

\section{Influence of spatial, thematic, and temporal resolution on pattern metrics}

The 2 main components of scale, viz. grain (e.g. spatial resolution of the data) and extent (e.g. geographic area of the study site), have been well studied and are

Table 5. Summary of 3D spatial pattern metrics applied in the reviewed literature. Of 5 studies in total, the major habitat types to which the metrics were applied were coral reef, mangrove, and seagrass. See Pittman et al. (2009) for description of common 3D spatial pattern metrics

\begin{tabular}{|lc|}
\hline Spatial pattern metric & No. of studies \\
\hline Landscape composition $\mathbf{- 8}$ metrics & 3 \\
Rugosity & 2 \\
Slope & 2 \\
Mean depth & 1 \\
Variance in depth & 1 \\
Standard deviation of depth & 1 \\
Slope of slope & 1 \\
Plan curvature & 1 \\
Fractal dimension & \\
\hline
\end{tabular}


known to affect the behavior of individual spatial pattern metrics, and therefore, the understanding of ecological relationships (Urban et al. 1987, Wiens 1989). For instance, as grain is increased with an unchanging extent, the number of patches in the landscape decreases (Lepczyk et al. 2007). Another often neglected map characteristic that can influence the results from spatial pattern metrics is the thematic resolution, e.g. the amount of detail in a map represented by the number of classes (Kendall \& Miller 2008, Castilla et al. 2009, Kendall et al. 2011, this Theme Section).

When thematic maps (e.g. benthic habitat maps) are used to represent structure in the marine environment, issues related to map accuracy, cartographic bias, error propagation, and uncertainty become increasingly important and must be assessed (Lunetta et al. 1991, Hess 1994, Shao \& Wu 2008) (Figs. 3 \& 4). Remotely sensed data are available in a broad range of spatial resolutions, and the resolution of the imagery used to derive spatial pattern metrics can affect the results of the subsequent analysis (Manson et al. 2003). Within the subset of seascape papers reviewed, the geographic extent ranged from a photo quadrat at $310 \mathrm{~cm}^{2}$ (Garrabou et al. 1998) to an estuarine region that extended along the entire coast of Queensland, Australia (Meynecke et al. 2008). Spatial resolution of the data ranged from a vector data set with an MMU of $4 \mathrm{~mm}^{2}$ (Garrabou et al. 2002) to a raster data set with a pixel size of $10 \mathrm{~m}$ (Meynecke et al. 2008). Prada et al. (2008) explored the effects of changing the grain size (e.g. $4 \mathrm{~m}^{2}$ and $400 \mathrm{~m}^{2} \mathrm{MMU}$ ) of habitat maps on $7 \mathrm{com}-$

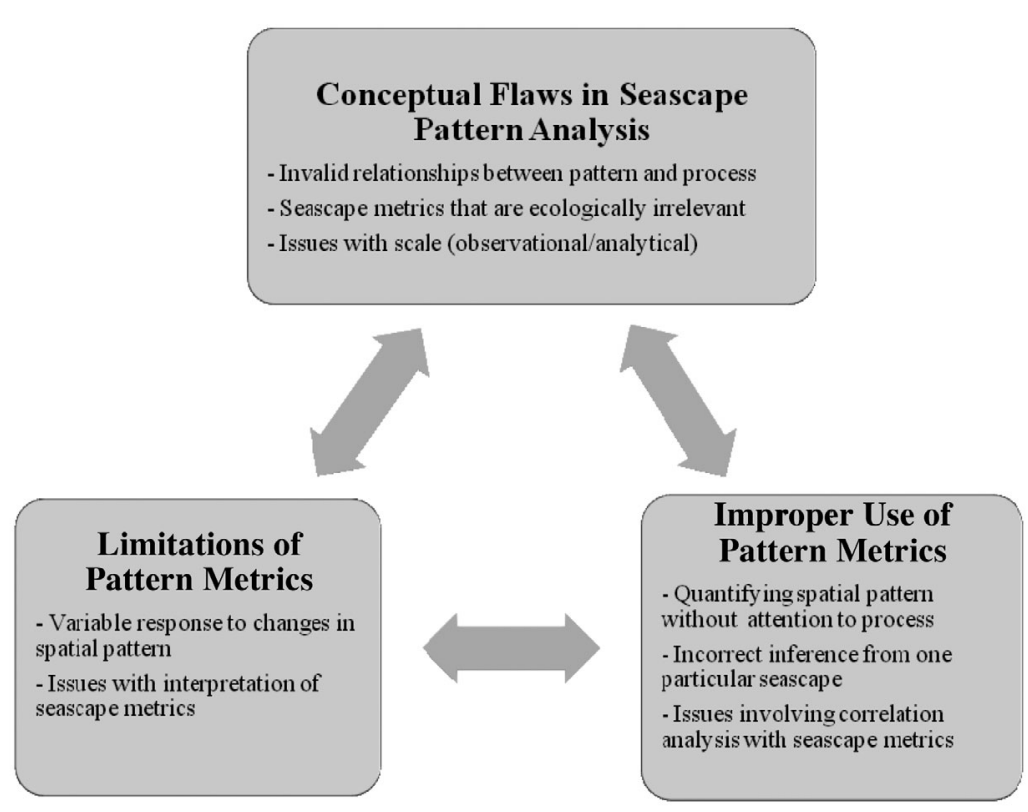

Fig. 3. Three types of problems in landscape analysis with pattern metrics: conceptual flaws, improper uses, and inherent limitations of landscape indices. Each type manifests in several forms that overlap with the other types. Modified from Li \& Wu (2004) monly used pattern metrics and found habitat richness to be the only metric that remained constant. Kendall \& Miller (2008) found that changing the spatial resolution of benthic habitat maps (100 $\mathrm{m}^{2}$ to $\left.4048 \mathrm{~m}^{2} \mathrm{MMU}\right)$ resulted in disproportionate changes in the area, perimeter, and other values among feature types, but had little effect on the relationship between seascape structure and fish community composition (Kendall \& Miller 2010). Subsequently, however, species level analyses by Kendall et al. (2011) found that different resolution maps changed the strength of correlations for several fish associated with coral reef edges and sandy areas, but results were consistent regardless of map resolution for comparisons involving area of seagrass and habitat diversity.

The Caribbean seascape ecology studies reviewed (Grober-Dunsmore et al. 2007, 2008, Pittman et al. $2007 a, b)$ used existing maps with predetermined cartographic characteristics including spatial and thematic resolution. Thematic resolution, as well as the quality and resolution of the imagery from which the map was derived, can have important impacts on the quantification of patch or habitat diversity. This is particularly important in studies of biodiversity patterns. Habitat diversity in terrestrial systems has been found to be positively correlated with animal species diversity, which is consistent with the 'habitat heterogeneity hypothesis' (Tews et al. 2004). In contrast, habitat richness and diversity of seascapes have not emerged as important explanatory variables for faunal diversity at the spatial scales examined in seascape ecology studies. This important difference between marine and terrestrial studies has not yet been sufficiently addressed in ecology and requires more detailed comparative and multi-scale analyses. In addition, very few studies (marine or terrestrial) have used diversity metrics such as taxonomic diversity and distinctness (Clarke \& Warwick 1999) to quantify seascape and landscape habitat diversity. Taxonomic indices account for diversity across hierarchical levels of classification that can be equally applicable to a benthic map classification as to a multi-species community. For instance, weightings can be assigned to different levels of a map classification, such that 4 classes from the same level in the hierarchy (e.g. sparse seagrass, dense seagrass, macroalgae, algal turf - all marine plants) would be less taxonomically diverse than 4 more structurally different classes (e.g. boulders, patch reef, seagrass, sand). Conventional diversity metrics such as patch richness and Shan- 


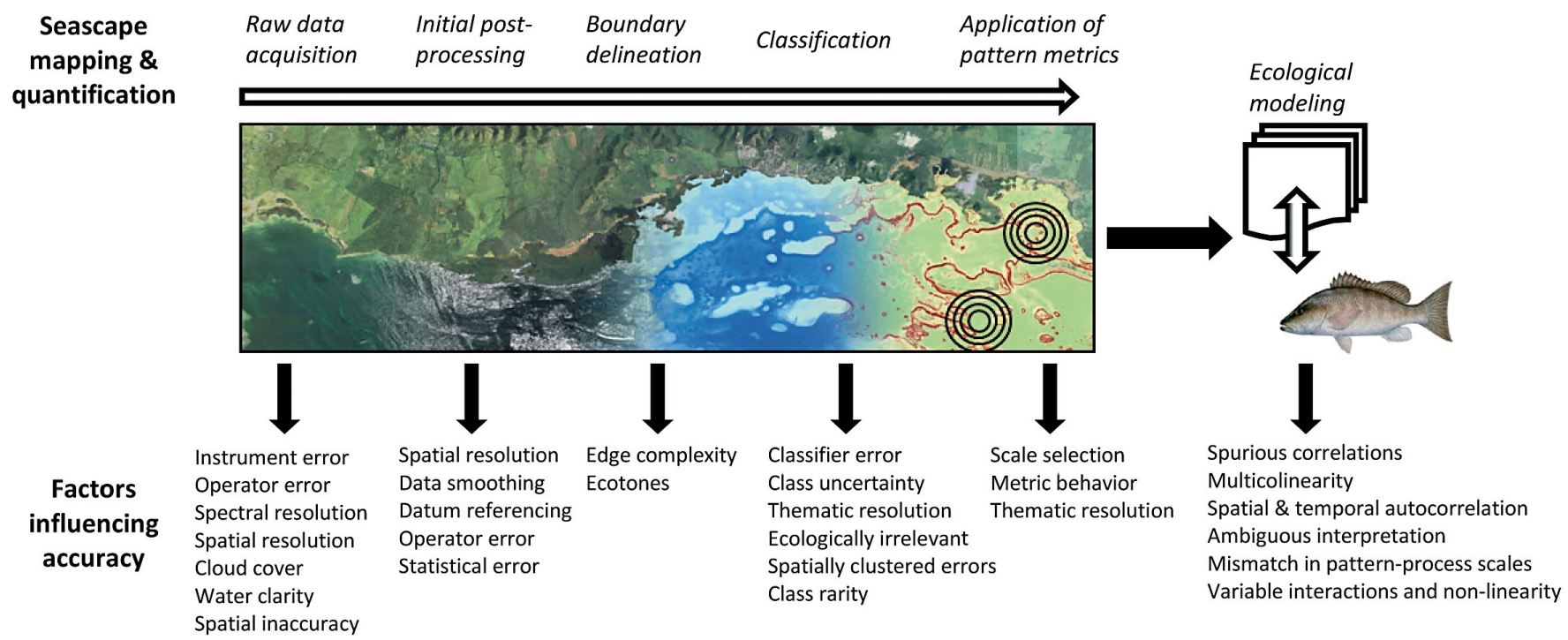

Fig. 4. Factors potentially influencing accuracy during the steps involved in seascape mapping, characterization, and quantification

non diversity would assign an equal score to these structurally and functionally different seascapes. Future studies in landscape ecology should examine a range of diversity metrics with consideration given to the functional relevance of the thematic resolution of any given habitat map.

\section{Data considerations and analytical techniques}

Potential misuses of pattern metrics can easily arise for 2 main reasons: (1) quantifying patterns without considering ecological processes and causal relationships, and (2) failing to deal with caveats of correlation analysis (Li \& Wu 2004). The first reason is selfexplanatory and an important consideration for all areas of ecology. The second reason requires some explanation and discussion of analytical solutions. Data in landscape ecology, particularly spatial pattern metrics, are typically non-normally distributed, exhibit multicollinearity, spatial autocorrelation, and often include irrelevant variables. Multicollinearity has implications for certain statistical modeling techniques, such as multiple regression (Graham 2003). Multicollinearity occurs because many of the metrics share some component (often geometric) derived from a core suite of interrelated measures such as patch area, edge length, shape, and inter-patch distance to quantify different attributes of spatial pattern often resulting in strong collinearity (positive and negative) between metrics (Li \& Reynolds 1993, Riitters et al. 1995). Nonetheless, similar metrics can still capture slightly different attributes of spatial structure, and a single metric may not capture sufficient structural variability (e.g. spatial arrangement and composition) to explain com- plex organism responses to spatial patterning (Cushman et al. 2008). Much effort has been directed toward finding parsimony amongst the wealth of spatial pattern metrics available (Riitters et al. 1995, Gustafson 1998, Cardille et al. 2005). Cushman et al. (2008) examined 49 class-level metrics and 54 landscape-level metrics applied to 3 geographically distinct regions and identified a reduced set of metrics that consistently described the major attributes of landscape configuration.

Exploratory analyses can be crucial to identifying a suite of potentially important patterns through correlative techniques as a precursor to refining the subsequent steps toward explicitly determining causality. Although the pattern-pattern approach is often criticized in science, it is clear that progress in ecology can be accelerated by first identifying and describing patterns (Underwood et al. 2000). We focus here on a brief review of multivariate statistical techniques that have been developed to increase interpretability of patternpattern relationships from analysis of complex multiscale ecological data sets (Table 3). We do not include linear regression, although we recognize its utility for modeling in landscape ecology, where it is sometimes used as a secondary step after orthogonal decomposition of multivariate data through ordination techniques. Our focus is not on the details of the algorithms themselves, but rather on highlighting the applications of the techniques in landscape ecology.

\section{Ordination}

Ordination is a family of techniques that reduces high dimensionality data into fewer variables, each of which represents a continuum or gradient in the data 
that may be visualized in a 2D or 3D plot. The derivative variables are composites of environmental data and can be used as predictor variables in ecological modeling. Principle components analysis (PCA) has frequently been used to reduce the large number of sometimes collinear pattern metrics into a more parsimonious suite of variables (McGarigal \& McComb 1995, Cushman et al. 2008). PCA has been used to reduce the dimensionality of the multivariate data and to describe seascape structure based on the size and significance of the component loadings. For example, Meynecke et al. (2008) regressed 3 principal components (PCs), representing independent gradients in coastline characteristics and seascape composition and connectivity, against reported catch of individual fish and crustacean species, to highlight the importance of wetland connectivity. However, Grober-Dunsmore et al. (2008) regressed PCs of seascape structure against reef fish variables and explained less variability than did individual pattern metrics. PCA is a useful tool, but is influenced by sample size and assumes that the suite of variables change linearly along underlying gradients (Gauch 1982). In addition, non-linearity and inclusion of many collinear variables can result in distorted ordinations using standard PCA (McGarigal \& Cushman 2000).

Non-metric multidimensional scaling (nMDS) is an ordination technique that does not assume linearity and uses a similarity matrix rather than a correlation or covariance matrix and where samples are ranked according to their similarity. Pittman et al. (2007b) applied cluster analysis and nMDS using Plymouth Routines in Multivariate Ecological Research (PRIMER) to characterize seascape types from a small selection of pattern metrics that measured seascape composition (abundance of patch types and overall patch richness). Similarity percentages (SIMPER) were calculated to quantify the similarities and dissimilarities of the seascape structure within and between seascape types. Canonical correspondence analysis $\left(\mathrm{CCA}_{i}\right.$ Jongman et al. 1995), a hybrid of ordination and multiple regression, has been used effectively in explaining patterns of variation in organism distributions. CCA performs well with non-orthogonal and collinear gradients, making it suitable for complex landscape ecology analyses (Cushman \& McGarigal 2002), and has been used as a secondary step in the variable selection process to calculate the statistical significance when a variable is added into a model (Cushman \& McGarigal 2004).

\section{Structural equation modeling}

Structural equation modeling (SEM) can provide accurate and meaningful models in the presence of multicollinearity by incorporating collinear variables and non-linear variables explicitly in the model, rather than excluding them, or combining them into orthogonal components (Graham 2003). In SEM, the overriding concept is that a correlation may not imply causation, but the existence of a causal relationship implies some correlation. The possibilities can be tested as competing hypotheses. Models can be built and visualized using path diagrams to represent the working hypothesis about the causal relationships among variables (Shipley 1999). The relative effect of 1 variable is communicated using a standardized path coefficient analogous to partial regression coefficients. Parameter estimation is done by measuring the goodness of fit between the actual data matrix (correlation or covariance) representing the relationships between variables and the estimated data matrix of the best fitting model. Pittman et al. (2004) used SEM and path models to explain spatial patterns in fish and prawn distributions and diversity as influenced by habitat structure at multiple spatial scales. SEM was used to decompose correlations into direct and indirect components and examine the relative importance of within-patch structure (leaf length, sediment grain size) versus seascape composition and configuration (represented by a set of spatial pattern metrics). Competing models were tested using a range of goodness of-fit statistics and a final model selected on the basis of overall performance of the measures of model fit.

\section{Machine-learning algorithms}

Over the past decade, many advanced algorithms have been developed to efficiently explore and model complex patterns in complex data (Hastie et al. 2009). Some of the most successful examples are 'ensemble' techniques that use many models developed through iterative training and testing to learn and improve upon the errors of predecessors (Elith et al. 2006). Tree-based ensemble techniques, such as boosted regression trees and random forests have recently been used to model fish-seascape relationships at a range of spatial scales and to assess the relative importance of variables, to model interactions between variables, and to identify ecological thresholds (Leathwick et al. 2006, Pittman et al. 2009, Knudby et al. 2010). These machine-learning techniques are robust to collinearity and the presence of irrelevant predictors and therefore do not require prior variable selection or data reduction. Additional machine-learning techniques that offer great utility include multivariate adaptive regression splines and neural networks (Linderman et al. 2004). 


\section{FUTURE MARINE APPLICATIONS OF SPATIAL PATTERN METRICS}

\section{Landscape ecology at the boundary of land and sea}

Landscape ecology approaches offer great promise for examining functionally important structural boundaries at the land-sea interface (Kneib 1994), and can extend the progress made with understanding and managing the land-water interface for terrestrial freshwater environments (Naiman \& Decamps 1997). Tidal wetlands including some saltmarshes and mangroves, where the land-sea interface is dynamic over the tidal cycle, present a unique challenge for the application of spatial pattern metrics. Measuring such dynamic structure would require the application of metrics over a time series of imagery or quantification of features that provide a reliable proxy. Adequately quantifying dynamic patterns, however, may require new metrics. The easily mapped shallow-water and semi-terrestrial environments at the land-sea interface offer great opportunities to develop, apply, and test pattern metrics. Several commonly used metrics in hydrology, such as drainage density and measures of dendritic network complexity and channel morphology, as well as patch-based metrics such as marshwater interface and edge:perimeter ratio have been applied successfully to examine the spatial ecology of saltmarshes (Kneib 1991, 1994, Feagin \& Wu 2006). Future remote sensing techniques will increase the thematic resolution of seascape maps, and new variables that reveal more detailed spatial patterns in soil and water conditions across saltmarsh seascapes could be quantified using spatial pattern metrics. The adaptation of conventional landscape indices together with new metrics that can account for dynamic linear features, changing water volumes, wave action, and edaphic variables may increase the ability of statistical models to predict the distribution of species and assemblages. Understanding the consequences of changing spatial patterning will increase our ability to predict the impact of human modifications to coastal environments and guide effective restoration activities (Feagin \& Wu 2006, Kelly et al. 2011).

\section{D seascape structure}

Detailed seafloor terrain models are becoming increasingly accessible and reliable with technological advances and the proliferation of marine remote sensing. The 3D models that result from seafloor acoustic, laser, and optical mapping provide an opportunity to examine the relationship between benthic morphology, including topographic complexity and marine organisms and communities (Brock \& Purkis 2009). Morphometrics commonly used in geomorphology and industrial engineering to quantify surface features and complexity have performed well as predictors of fish diversity and species distributions across coral reef seascapes (Wedding et al. 2008, Pittman et al. 2009). The current limitation with morphometrics, and similarly with many of the spatial pattern metrics, is the lack of information on the ecological mechanisms that drive the pattern-pattern relationships. Nevertheless, inclusion of morphometrics in the suite of metrics applied to seascapes will likely offer new insights in the study of the reciprocal link between pattern and process (McGarigal et al. 2009).

\section{Quantifying seascape change}

Spatial pattern metrics combined with remote sensing data offer a cost-effective suite of spatial tools for surveillance and monitoring of seascape change. Remotely sensed imagery to document change in marine and coastal habitats over time is becoming increasingly important as anthropogenic stresses change coastal environments. Shallow water marine ecosystems such as seagrass, salt marsh, coral reef, and mangrove systems are globally threatened with an estimated loss of $30 \%$ in the past few decades (Valiela et al. 2009, Waycott et al. 2009). Detection of coastal habitat changes may be greatly enhanced by the application of spatial pattern metrics because they can provide important information beyond simple estimates of areal losses and gains. Habitat change can be a spatially complex process. Pattern metrics can quantify fragmentation rates and identify threshold effects or tipping points in ecosystem function (Grober-Dunsmore et al. 2009). For example, Manson et al. (2003) applied 7 spatial metrics to analyze mangrove change in Queensland, Australia, between 1973 and 1999 and found significantly altered spatial configuration, with implications for the movement and dispersal of marine fauna. With rapid loss and alteration of coastal ecosystem structure underway, it is now imperative to find cost-effective and reliable ways to quantitatively monitor changes and predict the ecological consequences.

\section{CONCLUSIONS}

Comparative studies and careful evaluation are required to support the judicious application of landscape ecology principles, concepts, and analytical techniques in the marine environment. Seascape structure (e.g. the composition and spatial configuration) of the marine environment is perceived differently, through the 
lens of landscape ecology, than conventional ecology. The development of spatial pattern metrics unique to the marine environment should be conducted with a strong ecological rationale in mind and with an aim to better understand the linkages between spatial patterns and ecological processes. Although we have focused entirely on shallow coastal applications, spatial pattern metrics could potentially offer new insights on pelagic ecosystems. Oceanic fronts, plankton patches, and spatial gradients in biophysical conditions across continental shelves are spatial patterns that have ecological consequences, yet are rarely quantified with pattern metrics. Seascape ecologists could benefit from lessons already learned in terrestrial landscape ecology. In particular, more effort should be focused on the a priori identification of ecologically relevant metrics to characterize spatial patterns. Research on the quantification of spatial patterns in the marine landscape should develop with an awareness of the evolution of terrestrial metrics, and with due attention to the limitations and pitfalls that arose as landscape pattern analysis became more widely applied and critically assessed. Future work on seascape metrics must achieve a balance between applying the fundamental metrics based on established terrestrial landscape ecology and expanding the theoretical basis of landscape ecology to address the unique set of challenges that must be confronted when working in the marine environment.

Acknowledgements. This research was supported by a National Science Foundation Dissertation Improvement Grant BCS-1003871, NOAA's Biogeography Branch, and the Coral Reef Conservation Program.

\section{LITERATURE CITED}

Andréfouët S, Claereboudt M, Matsakis P, Pages J, Dufour P (2001) Typology of atoll rims in Tuamotu Archipelago (French Polynesia) at landscape scale using SPOT HRV images. Int J Remote Sens 22:987-1004

Andréfouët S, Robinson J, Hu C, Feldman G, Salvat B, Payri C, Muller-Karger F (2003) Influence of the spatial resolution of SeaWiFS, Landsat-7, SPOT, and International Space Station data on estimates of landscape parameters of Pacific Ocean atolls. Can J Remote Sens 29:210-218

Bartholomew A, Bohnsack J, Smith S, Ault J, Harper D, McClellan D (2008) Influence of marine reserve size and boundary length on the initial response of exploited reef fishes in the Florida Keys National Marine Sanctuary, USA. Landsc Ecol 23:55-65

Boström C, Jackson E, Simenstad C (2006) Seagrass landscapes and their effects on associated fauna: a review. Estuar Coast Shelf Sci 68:383-403

Boström C, Pittman SJ, Simenstad C, Kneib RT (2011) Seascape ecology of coastal biogenic habitats: advances, gaps, and challenges. Mar Ecol Prog Ser 427:191-217

Botequilha Leitão A, Miller J, Ahern J, McGarigal K (2006) Measuring landscapes: a planner's handbook. Island Press, Washington, DC
Brennan JM, Bender DJ, Contreras TA, Fahrig L (2002) Focal patch landscape studies for wildlife management: optimizing sampling effort across scales. In: Liu J, Taylor WW (eds) Integrating landscape ecology into natural resource management. Cambridge University Press, Cambridge, p 68-91

Brock JC, Purkis SJ (2009) The emerging role of LiDAR remote sensing in coastal research and resource management. J Coast Res (Spec Issue) 53:1-5

Browder J, May LN, Rosenthal A, Gosselink JG, Baumann RH (1989) Modeling future trends in wetland loss and brown shrimp production in Louisiana using thematic mapper imagery. Remote Sens Environ 28:45-59

$>$ Burrough PA (1981) Fractal dimensions of landscapes and other environmental data. Nature 294:240-242

Cardille J, Turner M, Clayton M, Gergel S, Price S (2005) METALAND: characterizing spatial patterns and statistical context of landscape metrics. Bioscience 55:983-988

Castilla G, Larkin K, Linke J, Hay GJ (2009) The impact of thematic resolution on the patch-mosaic model of natural landscapes. Landsc Ecol 24:15-23

> Clarke KR, Warwick RM (1999) The taxonomic distinctness measure of biodiversity: weighting of step lengths between hierarchical levels. Mar Ecol Prog Ser 184:21-29

> Costanza R, Sklar FH, White ML (1990) Modeling coastal landscape dynamics. Bioscience 40:91-107

Cushman SA, McGarigal K (2002) Hierarchical, multi-scale decomposition of species-environment relationships. Landsc Ecol 17:637-646

Cushman S, McGarigal K (2004) Patterns in the species-environment relationship depend on both scale and choice of response variables. Oikos 105:117-124

Cushman SA, McGarigal K, Neel MC (2008) Parsimony in landscape metrics: strength, universality, and consistency. Ecol Indic 8:691-703

> Drew CA, Eggleston DB (2008) Juvenile fish densities in Florida Keys mangroves correlate with landscape characteristics. Mar Ecol Prog Ser 362:233-243

> Elith J, Graham CH, Anderson RP, Dudik M and others (2006) Novel methods improve prediction of species' distributions from occurrence data. Ecography 29:129-151

Feagin RA, Wu XB (2006) Spatial pattern and edge characteristics in restored terrace versus reference salt marshes in Galveston Bay. Wetlands 26:1004-1011

Forman RTT, Godron M (1986) Landscape ecology. John Wiley, New York, NY

> Garrabou J, Riera J, Zabala M (1998) Landscape pattern indices applied to Mediterranean subtidal rocky benthic communities. Landsc Ecol 13:225-247

Garrabou J, Ballesteros E, Zabala M (2002) Structure and dynamics of north-western Mediterranean rocky benthic communities along a depth gradient. Estuar Coast Shelf Sci 55:493-508

> Gauch HG Jr (1982) Noise reduction by eigenvector ordinations. Ecology 63:1643-1649

Graham MH (2003) Confronting multicollinearity in ecological multiple regression. Ecology 84:2809-2815

Grober-Dunsmore R, Frazer TK, Lindberg WJ, Beets J (2007) Reef fish and habitat relationships in a Caribbean seascape: the importance of reef context. Coral Reefs 26: 201-216

Grober-Dunsmore R, Frazer TK, Beets JP, Lindberg WJ, Zwick P, Funicelli NA (2008) Influence of landscape structure, on reef fish assemblages. Landsc Ecol 23:37-53

Grober-Dunsmore R, Pittman SJ, Caldow C, Kendall MS, Frazer TK (2009) A landscape ecology approach for the study of ecological connectivity across tropical marine 
seascapes. In: Nagelkerken I (ed) Ecological connectivity among coral reef ecosystems. Springer, New York, NY p 493-529

Gustafson EJ (1998) Quantifying landscape spatial pattern: What is state of the art? Ecosystems 1:143-156

Hastie T, Tibshirani R, Friedman J (2009) Elements of statistical learning: data mining, inference and prediction. Springer-Verlag, New York, NY

> Hess G (1994) Pattern and error in landscape ecology: a commentary. Landsc Ecol 9:3-5

> Hinchey EK, Nicholson MC, Zajac RN, Irlandi EA (2008) Marine and coastal applications in landscape ecology. Landsc Ecol 23:1-5

Jongman R, Ter Braak C, van Tongeren O (1995) Data analysis in community and landscape ecology. Cambridge University Press, Cambridge

Kelly M, Tuxen KA, Stralberg D (2011) Mapping changes to vegetation pattern in a restoring wetland: finding pattern metrics that are consistent across spatial scale and time. Ecol Indic 11:263-273

Kendall MS, Miller TJ (2008) The influence of spatial and thematic resolution on maps of a coral reef ecosystem. Mar Geod 31:75-102

Kendall MS, Miller TJ, Pittman SJ (2011) Patterns of scaledependency and the influence of map resolution on the seascape ecology of reef fish. Mar Ecol Prog Ser 427: 259-274

Kendall MS, Miller TJ (2010) Relationships among map resolution, fish assemblages, and habitat variables in a coral reef ecosystem. Hydrobiologia 637:101-119

Kneib RT (1991) Flume weir for quantitative collection of nekton from vegetated intertidal habitats. Mar Ecol Prog Ser 75:29-38

Kneib RT (1994) Spatial pattern, spatial scale, and feeding in fishes. In: Stouder D, Fresh K, Feller R (eds) Theory and application in fish feeding ecology. The Belle W. Baruch Library in Marine Science Number 18. University of South Carolina Press, Columbia, SC, p 171-185

Knudby A, LeDrew E, Brenning A (2010) Predictive mapping of reef fish species richness, diversity and biomass in Zanzibar using IKONOS imagery and machine-learning techniques. Remote Sens Environ 114:1230-1241

Krummel JR, Gardner RH, Sugihara G, O'Neill RV, Coleman PR (1987) Landscape patterns in a disturbed environment. Oikos 48:321-324

> Leathwick JR, Elith J, Francis MP, Hastie T, Taylor P (2006) Variation in demersal fish species richness in the oceans surrounding New Zealand: an analysis using boosted regression trees. Mar Ecol Prog Ser 321:267-281

> Legendre P, Fortin MJ (1989) Spatial pattern and ecological analysis. Vegetatio 80:107-138

Lepczyk CA, Hammer RB, Radeloff VC, Stewart SI (2007) Spatiotemporal dynamics of housing growth hotspots in the North Central U.S. from 1940 to 2000. Landsc Ecol 22: 939-953

Li XZ, Mander U (2009) Future options in landscape ecology: development and research. Prog Phys Geogr 33:31-48

Li H, Reynolds J (1993) A new contagion index to quantify spatial patterns of landscapes. Landsc Ecol 8:155-162

Li H, Reynolds JF (1995) On definition and quantification of heterogeneity. Oikos 73:280-284

> Li H, Wu J (2004) Use and misuse of landscape indices. Landsc Ecol 19:389-399

> Linderman M, Liu J, Qi J, An L, Ouyang Z, Yang J, Tan Y (2004) Using artificial neural networks to map the spatial distribution of understorey bamboo from remote sensing data. Int J Remote Sens 25:1685-1700
Lunetta RS, Congalton RG, Fenstermaker LK, Jensen JR, McGwire KC, Tinney LR (1991) Remote sensing and geographic information system data integration-error sources and research issues. Photogramm Eng Remote Sens 57:677-687

Mandelbrot BB (1982) the fractal geometry of nature. WH Freeman, New York, NY

Manson FJ, Loneragan NR, Phinn SR (2003) Spatial and temporal variation in distribution of mangroves in Moreton Bay, subtropical Australia: a comparison of pattern metrics and change detection analyses based on aerial photographs. Estuar Coast Shelf Sci 57:653-666

> Manson FJ, Loneragan NR, Harch BD, Skilleter GA, Williams L (2005) A broad-scale analysis of links between coastal fisheries production and mangrove extent: a case-study for northeastern Australia. Fish Res 74:69-85

McGarigal K, Cushman S (2000) Multivariate statistics for wildlife and ecology research. Springer-Verlag, New York, NY

> McGarigal K, McComb WC (1995) Relationships between landscape structure and breeding birds in the Oregon Coast Range. Ecol Monogr 65:235-260

McGarigal K, Cushman S, Neel M, Ene E (2002) FRAGSTATS: spatial pattern analysis program for categorical maps. Available at www.umass.edu/landeco/research/ fragstats/fragstats.html

> McGarigal K, Tagil S, Cushman S (2009) Surface metrics: an alternative to patch metrics for the quantification of landscape structure. Landsc Ecol 24:433-450

> Meynecke JO, Lee SY, Duke NC (2008) Linking spatial metrics and fish catch reveals the importance of coastal wetland connectivity to inshore fisheries in Queensland, Australia. Biol Conserv 141:981-996

Naiman RJ, Decamps H (1997) The ecology of interfacesriparian zones. Annu Rev Ecol Syst 28:621-658

- Neigel JE (2003) Species-area relationships and marine conservation. Ecol Appl 13:138-145

- O'Neill RV, Krummel JR, Gardner RH, Sugihara G and others (1988) Indices of landscape pattern. Landsc Ecol 1:153-162

Pittman SJ, McAlpine CA, Pittman KM (2004) Linking fish and prawns to their environment: a hierarchical landscape approach. Mar Ecol Prog Ser 283:233-254

Pittman SJ, Caldow C, Hile SD, Monaco ME (2007a) Using seascape types to explain the spatial patterns of fish in the mangroves of SW Puerto Rico. Mar Ecol Prog Ser 348: 273-284

Pittman SJ, Christensen JD, Caldow C, Menza C, Monaco ME (2007b) Predictive mapping of fish species richness across shallow-water seascapes in the Caribbean. Ecol Model 204:9-21

Pittman SJ, Costa BM, Battista TA (2009) Using LiDAR bathymetry and boosted regression trees to predict the diversity and abundance of fish and corals. J Coast Res (Spec Issue) 53:27-38

> Prada MC, Appeldoorn RS, Rivera JA (2008) The effects of minimum map unit in coral reefs maps generated from high resolution side scan sonar mosaics. Coral Reefs 27: $297-310$

> Riitters KH, O'Neil RV, Hunsaker CT, Wickham JD and others (1995) A factor analysis of landscape pattern and structure metrics. Landsc Ecol 10:23-39

Robbins B, Bell S (1994) Seagrass landscapes: a terrestrial approach to the marine subtidal environment. Trends Ecol Evol 9:301-304

Romme WH (1982) Fire and landscape diversity in subalpine forests of Yellowstone National Park. Ecol Monogr 52: $199-221$ 
Shao G, Wu J (2008) On the accuracy of landscape pattern analysis using remote sensing data. Landscape Ecol 23: 505-511

Shipley B (1999) Testing causal explanations in organismal biology: causation, correlation and structural equation modelling. Oikos 86:374-382

Sleeman JC, Kendrick GA, Boggs GS, Hegge BJ (2005) Measuring fragmentation of seagrass landscapes: Which indices are most appropriate for detecting change? Mar Freshw Res 56:851-864

Teixido N, Garrabou J, Arntz WE (2002) Spatial pattern quantification of Antarctic benthic communities using landscape indices. Mar Ecol Prog Ser 242:1-14

Teixido N, Garrabou J, Gutt J, Arntz WE (2007) Iceberg disturbance and successional spatial patterns: the case of the shelf Antarctic benthic communities. Ecosystems 10: $143-158$

Tews J, Brose U, Grimm V, Tielbörger K, Wichmann MC, Schwager M, Jeltsch F (2004) Animal species diversity driven by habitat heterogeneity/diversity: the importance of keystone structures. J Biogeogr 31:79-92

Turner MG (1989) Landscape ecology: the effect of pattern on process. Annu Rev Ecol Syst 20:171-197

Turner SJ, Hewitt JE, Wilkinson MR, Morrisey DJ, Thrush SF, Cummings VJ, Funnell G (1999) Seagrass patches and landscapes: the influence of wind-wave dynamics and hierarchical arrangements of spatial structure on macrofaunal seagrass communities. Estuar Coasts 22:1016-1032

Turner MG, Gardner RH, O'Neill RV (2001) Landscape eco-

Submitted: June 10, 2010; Accepted: March 7, 2011 logy in theory and practice: patterns and processes. Springer, New York, NY

Underwood A, Chapman M, Connell S (2000) Observations in ecology: You can't make progress on processes without understanding the patterns. J Exp Mar Biol Ecol 250: 97-115

Urban DL, O'Neill RV, Shugart HH Jr (1987) Landscape ecology. Bioscience 37:119-127

Valiela I, Kinney E, Culbertson J, Peacock E, Smith S (2009) Global losses of mangroves and saltmarshes. In: Duarte CM (ed) Global loss of coastal habitats: rates, causes and consequences. Fundación BBVA, Bilbao, Spain p 107-138

Waycott M, Duarte CM, Carruthers TJB, Orth RJ and others (2009) Accelerating loss of seagrasses across the globe threatens coastal ecosystems. Proc Natl Acad Sci USA 106: 12377-12381

> Wedding LM, Friedlander AM (2008) Determining the influence of seascape structure on coral reef fishes in Hawaii using a geospatial approach. Mar Geod 31:246-266

- Wedding LM, Friedlander AM, McGranaghan M, Yost R, Monaco M (2008) Using bathymetric LIDAR to define nearshore benthic habitat complexity: implications for management of reef fish assemblages in Hawaii. Remote Sens Environ 112:4159-4165

Wiens JA (1989) Spatial scaling in ecology. Funct Ecol 3: 385-397

Wiens JA (2002) Riverine landscapes: taking landscape ecology into the water. Freshw Biol 47:501-515

Proofs received from author(s): April 4, 2011 